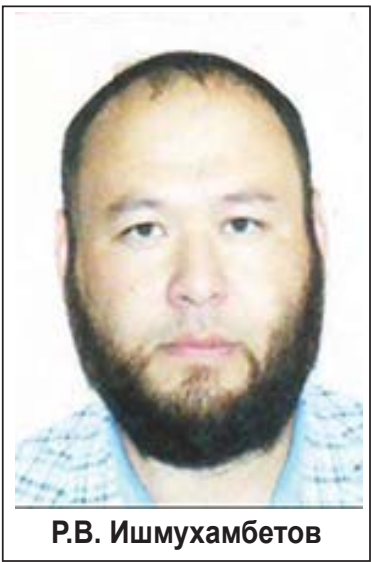

DOI 10.23671/VNC.2020.1.56944

УДК $94+39$

\title{
МЕЖДУ РЕКАМИ КУБАНЬЮ, ТЕРЕКОМ И УРАЛОМ-ЯИКОМ (Полиэтничная Букееевская орда XIX в.)
}

\author{
P.В. Ишмухамбетов"
}

\begin{abstract}
Аннотация. Статья посвящена истории и этническим традициям, служилому статусу в среде оседавших тюркских кочевников в междуречье Волаи и Яика-Урала. Рассматривается он, в первую очередь, на примере так называемых нами «ногай-казахов», субэтноса в составе западной группы казахов, который по сию пору очень малоисследован. Рассматриваются предыстория и вопросы сложения этой особой субэтнической группы, прежняя социальная роль и нынешнее положение потомков прежних служилых, их нынешнее самосознание и предполагаемые перспективы развития.

Ключевые слова: казахи, ногайцы, служилые группы, субэтнос, Букеевская орда.
\end{abstract}

Вполне известно, на каком сложном перепутье находятся сейчас и «историческая этнология», и «этническая история». Новые их пути - на рельсах новой «ареальности» (в нашем случае - в степях от Черного и Азовского до Каспийского и Аральского морей). А также в гибких связях региональности с генетикой, в т. н. «геномике».

И вновь намеченная картина может оказаться весьма неожиданной и необычной. В са́мом деле: даже, казалось бы, весьма близкие народы-этносы могут оказаться весьма различными по происхождению их базовых частей.

При этом никак и ничуть не исключены их дальнейшие контакты и взаимосвязи, только не в седой древности, а в новое и новейшее время. С другой стороны, через посреднические фракторы (ногайцы - лишь один тому яркий пример) могут оказаться сопряженными в ходе развития таких отдаленных территорий, как Кавказ и Казахстан.

Выразим свою твердую уверенность, что пришла пора пересмотреть классическую старинную литературу по Югу России, покончить с отвлекающими спорами «праймордиалистов» с «конструктивистами» и произвести новые изыскания в архивах и полевой экспедиционной работе.

Занимаясь длительное время проблемами служилости прежних кочевников Нижневолжья, мы на сей раз провели архивные изыскания. А вслед за тем (и это главное) получили редкостный шанс прочувствовать ощутимые следы данного явления лично. Это произошло во время наших полевых изысканий 25-28 августа 2015 г. в местах компактного проживания потомков служилых групп в составе казахов - в крайней западной точке Казахстана, на границе с Астраханской и Волгоградской областями России.

Обозначенному кругу вопросов мы и посвятим нашу нынешнюю публикацию, предприняв рассмотрение научного материала от событий давних веков прямо к современности. И следуя продвижению от первоначального (хотя и солидно-классического, у авторов-энциклопедистов) изучения до «продвинутого», модернизированного, разнопланового и структурно-многоаспектного.

Возвращаемся мы еще и к теме границы и фрронтира, о которых писали ранее [7, с. 19-20]. Данная статья была подготовлена с попыткой восполнить ряд обнаруженных пробелов в раскрытии принятой нами к рассмотрению темы. Приступая непосредственно к изложению собранного нами материала, мы отметим, что тема, безусловно, нуждается в дальнейшем внимании, изучении и развитии.

Итак, что может связывать такие географически далекие, казалось бы, территории, как Осетия и Казахстан? Однако связь таковая имеется, она осуществляется через потомков ногайцев, которые прежде населяли упомянутые земли, затем небольшой своей частью вошли в состав казахского народа под именем родового объединения ногайказах, правда, по сию пору не входящего в жузы. История ногайско-осетинских связей насчитывает не одно столетие. Еще предшественники и предки ногайцев - половцы имели многочисленные и тесные связи с аланами. Показателем проникновения асского-аланского компонента к предкам ногайцев, по-видимому, следует считать наличие родового объединения асопа (ас-опа) у половцев. И затем племенного объединения ас уже у ногайцев. Интересны сведения о бытовании некоторых отдельных нартовских сюжетов в ногайском фрольклоре [18, с. 36-43].

Имелись и собственно ногайские эпические сюжеты, связанные территориально с Осетией. Так, в ногайском дестане (эпических сказаниях) о Мусекебатыре, действие которого частично происходит в вышеуказанных местах, описывается некий Борахан:

Кто я родом - спросил ты меня?

Я Нукая сын из рода Уйсин.

Перед боем не содрогался я,

Видя девушек, не спотыкался я.

* Иимухамбетов Рамиль Валитович - соискатель кафредры истории России Астраханского государственного универсиmema (ramil_0186@mail.ru). 
Неутомим, как Тулпар,

Нартов я на битву водил.

Ради жизни братьев моих

Я неверных войско разбил.

Борагана увалы я отстоял,

Бора-хана я защитил. [16]

Эту легендарную личность (т. е. Бора-хана) в легендах именовали властелином Татартупа, что находился на территории Осетии [3, с. 49-55].

Сама же местность Татартуп, иначе Татар-топ, фигурировала в ногайских родословных (ног. шеджере) как та, в которой жил прародитель ногаев едишкульцев (и едисанцев), чьей женой была некая Токсаба [24, с. 55, 436]. На самом же деле общеизвестно, что Токсаба исходно - это племенной этноним в составе западно-кыпчакского, или половецкого (куманского) объединения [5, с. 93].

Согласно этногенетическим преданиям ногайцев, отраженным в традиционных родословных - шеджере, общие предки ногай-казахов и таркинских ногайцев происходили из объединения едишкуль, связывали свое происхождение именно с Мусеке-батыром из рода уйсин, как это видно в приводимых Г.М.-Р. Оразаевым архивных документах $[17$, с. 214$]$.

Подкрепляются упомянутые данные тем, что род уйсин называется у ногайцев еще и уйсен-кыпчак и входит в кыпчакский куб [19]. Немаловажно и то, что, согласно данным В.В. Трепавлова, в составе ногайцев был род борган-кыпчак (бурганкипчакское родство) [24, с. 488]. Добавим, что и В.Б. Виноградовым было высказано мнение, что борганы - это средневековые кыпчаки, предки ногаев, тем более что ингуши связывали их именно с ногаями [ 3, с. 49-55]. Память об исходе из Крыма либо Кавказа (Кубани) вообще является центральным сюжетом в родословных-шеджере у потомков кыпчако-ногайских групп в Башкирии и Татарстане [2, с. 36, с. 72; 13, с. 60; 358-359]

И действительно, именно представители кыпчакского ногайского куба из едишкульцев хранили память о переселениях из Крыма с Мамаем, как и об «увалах Борагана». Очевидно, что предания о Бора-хане и Мусеке-батыре из рода уйсин для этой группы играли особую роль в их родовой самоидентифрикации.

Общеизвестно, что родословные-шеджере и предания являются не основным и полноценным источником, но второстепенным, нуждаются в критическом анализе и сличении. Однако в условиях, когда прочих данных почти не имеется, при наличии многочисленных сходных сюжетов разного происхождения, именно они могут пролить свет на раннюю этническую историю того или иного народа. Мысль об этом высказал Р.Х. Керейтов, ссылаясь на С.М. Абрамзона [12, с. 36].

Таким образом, данная во многом малоиссле- дованная тема нуждается в дальнейшем изучении.

Согласно данным Г.А. Кокиева, ногайцы проживали рядом с асами-дигорцами в XIV веке в Oceтии, многочисленные следы пребывания ногайцев в данной местности сохранены в топонимике и преданиях [13].

Связи двух народов продолжались и в более позднее время. Переселенцы в новое время в Осетии могли происходить из аулов Каясула и Иргаклы, по предположениям В.М. Викторина ${ }^{1}$. И Б.А. Алборов в своем исследовании отмечал сильное ногайское влияние у моздокских осетин [1].

В целом разнообразные связи ногайцев и осетин неоднократно рассмотрены Д.С. Кидирниязовым [13].

Однако вернемся к судьбе той группы «кипчакского ногайского куба» из едишкульцев. Они, после многочисленных миграций раннего средневековья и ухода на Волгу, вернулись во главе с потомками Исмаила-мурзы в прикавказские степи, закрепившись уже в Кумыкии, заключив с шамхалом Тарковским военный союз.

Во время русско-турецких военных столкновений эта группа, возлавляемая мурзами Темирбулатовыми, видимо, стремясь избежать военных столкновений, то выходила из российского подданства, уходя на Кубань, то возвращалась к Кизляру [4], пока российскими властями не было принято решение о переселении их. Так, после пребывания под Астраханью данную группу отправили в Оренбуржье и поселили в «Кундровской Слободе». Однако уже в сентябре 1747 г. часть этой группы бежала к казахам Младшего жуза в числе «лучших 25 ceмей» $[23$, с. 13, с. 127]

Это событие дало начало образованию рода ногай в составе западных казахов.

В са́мом нач. XIX в. в Волго-Уральском междуречье было создано новое, полуавтономное по отношению к Российской империи, Букеевское ханство, именуемое также Внутренней ордой. Подчеркнем сразу же редко выделяемую полиэтничность Букеевской орды, которая отмечена авторами, начиная с XIX столетия, вскользь либо лишь намечена в исследованиях. И именно ханство Букея стало особенным явлением в истории региона по многим своим характеристикам, в том числе и тем, что в нем прежних служилых «туленгутов» заменили новые пришельцы ногайского, татарского и иного происхождения.

И на их основе спустя несколько поколений и образовались субэтнические объединения по образцу традиционных казахских родов - «руы, рулары». А само понятие «ру» (каз. руы, ног. ырув) - явление в среде казахов (как и прочих кочевых прежде тюрков) особое.

Подобные вещи отмечали еще ученые - «первопроходцы» в изучении Букеевской орды (П.И. Небольсин, А.Ф. Терещенко, А.Н. Харузин). Позднее

${ }^{1}$ Такое предположение было высказано им в нашей беседе, cocm. 10.07.2019 д. 
этой и близкими проблемами занимались и занимаются поныне как российские, так и казахстанские исследователи (Б.З. Аспандияров, С.З. Зиманов, А.Ю. Быков, А.В. Ремнев). Специально ногайскоказахские связи позднего времени этнической истории двух народов рассматривал, так или иначе, ряд казахстанских исследователей (А.И. Исин, Ж.М. Сабитов, А.Т. Сарай). Обращались к таким сюжетам и авторы, живущие и работающие в само́м регионе Нижневолжья и зоне «Богдо́-Баскунчак» ( В.М. Викторин, Э.Ш. Идрисов, А.Ш. Курумбаев ).

Поднимаются данные вопросы и в глобальной компьютерной сети «Интернет». Но, к огорчению, именно сейчас там «межкыпчакская тема» оказывается, чаще всего, полемически заострена [8, с. 399-400].

Особенность принятых служилых групп в Букеевской орде - отсутствие официального статуса, что не лишало статуса особого внутреннего. Зависимость и служба у этих групп проявилась в покровительстве на суде и наделении землей прежде и более всех прочих. Вместе с тем ногай-казахи в отличие от туленгутов платили налоги [10].

Итак, «принятие» изначально иноэтничных групп в казахское общество происходило при помощи некоего «приемного приговора» (устного либо письменного) [7].

Неказахское этническое происхождение означало отсутствие и незакрепленность в обществе связей и позволяло эффрективно выполнять полицейские и прочие репрессивные функции. Во время переселения в Волго-Уралье и при восстаниях группы смогли доказать свою полезность.

Вместе с тем необходимо отметить и «двойственное поведение», а именно наличие их представителей и в рядах протестующих при волнениях, о чем известно из имеющихся документов [6, с. 558].

Такими были протестные движения Каип-Гали Ишимова (1828-1829 гг.), Исатая Тайманова (18361838 гг.) и затем Аппаса Кушаева (1838-1842 гг.). Самым заметным оказалось именно движение батыра Исатая.

Джангир-хан сам награждал приближенных, скрывая факт жалования землею от властей, отчего и документов о наделении ханом в архивах нами не обнаружено. Но есть свидетельства косвенные - из доклада [6, с. 812].

Отношения рода ногай с ханами таким образом демонстрируют служилость и зависимость.

Люди из рода «ногай» были поверенными еще у хана Букея и защищали его наряду с казаками [6, с. 167]. Во время же правления Джангира, согласно формулярным спискам, букеевские ногайцы - старшины Акбулат Сангрыков и Джумали Юсупов активно участвовали в предотвращении ухода за Урал казахов при волнениях Каип-Гали Ишимова [6, c. 578-579]. Служба курьером у хана Бикжана Ниязова, тоже представителя рода «ногай», который доставлял переписку хана, указывает на особое доверие [6, с. 593]. Кроме того, именно ногай-казахи содержали в Букеевской орде многие почтовые станции [6, с. 723]. Участвовали активно ногай-казахи и в подавлении восстания Исатая Тайманова, что немаловажно при установлении служилости и зависимости, о чем мы писали и ранее [9]. Также и кочевание ногай-казахов вместе с ханом, ходжинцами и туленгитами вне прочих показывает особое их социальное положение [9, с. 44].

Вместе с этим ногайский род мог выражать недовольство выступлением против ханской власти. И сам же возглавлявший протест ногаец Аппас Кушаев извещал в своих показаниях о том, что исходно находился у Джангира «в услужении» [6, с. 558].

Итак, потомки ногайцев-едишкульцев стали служить ханам, составив особое сословие, получая в награду землю и прочие привилегии. В то же время к ним примкнула еще одна группа татарского (мишарского) происхождения - калпаки [7], восприняв их тамгу и частично, видимо, функции.

Кроме того, имелась и служилая группа туленгутов иного статуса, к которой примкнула еще одна группа ногайского происхождения - букеевские карагашногаи [15]. Впоследствии, утратив служилое положение, все перечисленные группы стали уже родовыми объединениями субэтнического характера среди казахов.

В сентябре 2015 г. нам совместно с доцентом В.М. Викториным удалось посетить потомков служилых групп. Ныне они в основном проживают компактно в сс. Хан-Ордасы, Сайхин, Джаныбек Западно-Казахстанской области. В их среде основным сюжетом преданий является именно служба хану. Именования «ногай», «карагаш» и «калпак» стали осознаваться, естественно, уже более как родовые, нежели национальные. В окружении западных казахов указанные группы уже называют себя казахами, признавая свои первоначально неказахские корни. При этом частично мы наблюдали и пережитки обычая эндогамии в силу близкого прежнего сословного статуса. Сохраняются в речи потомков и отдельные ногайские и татарские слова [19].

Часть ногайцев-едишкульцев была переселена в Оренбуржье с Кавказа, откуда некоторые из них перешли в Младший жуз казахов. Полвека спустя, уже в Букеевской орде их потомки составили сословную группу ногай-казахов, к которой присоединились и калпаки, которые были потомки татар. Эта «внутренняя служилость» в их лице, как особый феномен, в «букеевском» казахском обществе и сыграла важную роль при социальных протестах. Российские власти же, не дававшие ей официального признания, сталкивались с нею, что подтверждают доказательства: как архивные, так и полевые. Потомки их ныне, став частью казахского этноса, все еще сохраняют отдельные субэтнические особенности. 


\title{
ЛИТЕРАТУРА
}

1. Алборов Б.А. Из фолькллора Моздокских осетин (Архив Б.А. Алборова, ЦГА РСО-А, Ф Р.759, Оп.1, Д. 30). URL: http:// mozdok-hutor.narod.ru/index/osobennosti3 b alborov/0-53

2. Ахметзянов М.И. Нугай Урдасы: татара халкының тари хи мирасы, икенче китап, Казан Татарстан китаб нэшрияты 2009351 б. (на татарском яз.)

3. Виноградов В.Б. Время, горы, люди. - Грозный, 1980 C.49-55

4. Грибовский В.В., Сень Д.В. «Кубанский вектор» во взаимоотношениях калмыков и ногайцев в первой полови не XVIII в. // Калмыки в многонациональной России: опыт четырех столетий. - Элиста: АПП «Джангар», 2008. С. 168-192.

5. Евстигнеев А.Ю. Куманы-куны, кто они // Общество. Среда. Развитue (Terra Humana), 2012. № 2. C. 91-97. 6. История Букеевского ханства. 1801-1852 г2.: сборник документов и материалов / Сост. Б.Т. Жанаев, В.И. Иноч кин, С.Х. Сагнаева. - Алматы: Дайк-пресс, 2002. 1120 с. 7. Иимухамбетов P.B. Феномен служилых групп Букеевской орды Каспийский регион // Каспийский регион: политика, экономика, культура. № 3 (52), 2017. С. 19-29.

8. Иимухамбетов Р.В. Поволжье и «половецкое наслед ство»: споры и конфликты в сети Интернет // XIII Конгресс антропологов и этнологов России: сб. материалов (Секция № 22 ). Казань, 2-6 июля 2019 г. / Отв. ред.: М.Ю. Мартынова. - Москва - Казань: ИЭА РАН, КФУ, Институт истории им. Ш. Марджани АН РТ, 2019. С. 399-400 .

9. Иимухамбетов Р.В. Восстание Исатая Тайманова 1836-1838 г2. во Внутренней (Букеевской) орде казахов и служилые группы ее населения, Каспийский регион: поли тика, экономика, культура, 2016. № 4(49). С. 39-47.

10. Иимухамбетов P.B. Букеевская орда : традиции, сословные и субэтнические структуры, «переход» идентич ностей // XIII Конгресс антропологов и этнологов России: Казань, 2-6 июля 2019 г. (Устный доклад : секция № 48, июля 2019 г.)

11. История Северо-Осетинской АССР. - Орджоникидзе 1987. T. 1.562 c.
12. Керейтов P. X.. Ногайцы. Особенности этнической истории и бытовой культуры. - Ставрополь: Сервисшкола. 2009. 421 с

13. Кидирниязов Д. С. Взаимоотношения ногайцев с народами Северо-Восточного Кавказа в XVI - начале XX в. - Махачкала, 2008. 295 с

14. Кузеев Р. Г. Происхождение башкирского народа. Этнический состав, история расселения. - М.: Наука, 1974. 576 с.

15. Курумбаев А.Ш. Этнические группы Букеевской Орды // Ногаеведческий сборник Актуальные вопросы истории и культуры ногайцев. Выпуск 1. - Астрахань: Изд - во «Color», 2013. С. 75-78.

16. Народный эпос сборник Дагестан в легендах и преданиях. - Махачкала, 2007. 47 с.

17. Оразаев Г.М.-P. Тюркоязычная деловая переписка на Сeверном Кавказе XVII-XIX вв. Исследование, тексты и комментарии. - Махачкала: Изд. ДНЦ РАН, 2007. 322 с.

18. Плаева З.К. Ногайский вариант нартовского предания о смерти Ацамаза. Нартоведение в XXI веке: современные парадигмы и интерпретации: сборник научных трудов. ФГБУН СОИГСИ ВНЦ РАН и РСО-А. - Владикавказ: ИПЦ СОИГСИ ВНЦ РАН И РСО-А, 2015. 266 c.

19. ПМА - Полевые экспедиционные материалы автора. Хранятся в его личном архиве.

20. Рычков П.И. Топограффия Оренбургской губернии . Спб.: Императорская Академия наук, 1762. 331 с.

21. Рязанов А.Ф. Восстание Исатая Тайманова (1836-1838 г2.). - Ташкент: Типолит, 1927. № 2. 103 с

22. Сабитов Ж. М. Ногайский компонент в этногенезе казахов //Молодой ученый, 2016. № 1. С. 589-591. URL https:// moluch.ru/archive/105/23264/ (дата обращения: 16.07.2019). 23. Сенатский архив. Т. 9. - СПб, 1901 2.

24. Трепавлов В.В. История Ногайской Орды / Отв. ред. М. А. Усманов. 2-е изд. - Казань: Издательский дом «Казанская недвижимость», 2016. 764 c.

25. Харузин А.Н. Киргизы Букеевской орды: антропологоэтнологич. очерк (Изв. Об-ва ЛЕА и Э при Московском унme. T. LXIII). Вып. I. - М.: Типогр. А. Левенсона и K०, 1889.

\section{BETWEEN THE RIVERS KUBAN, TEREK AND URAL-YAIK. (Polyetnic Bukey horde of the XIX century)}

\author{
R.V. Ishmukhambetov \\ Applicant, Department of Russian History, Astrakhan State University (ramil_0186@mail.ru).
}

\begin{abstract}
The article is devoted to the history, ethnic traditions and serving status among the settled Turkic nomads in the interfluve of the Volga and Yayik-Ural rivers. It is primarily considered through the example of the so-called "NogaiKazakhs», a sub-ethnos which belonging to the western group of the Kazakhs, which has been little studied until the present day. The prehistory and issues of the formation of this special sub-ethnic group, the former social role and the current status of the former servicemen's descendants, their present self-consciousness and the expected development prospects are considered.
\end{abstract}

Keywords: кazakhs, nogai, service groups, subethnos, Bukeyev horde.

\section{REFERENCES}

1. Alborov B.A. Iz fol'klora Mozdokskikh osetin (Arkhiv B.A. Alborova, TsGA RSO-A, F R.759, Op.1, D. 30). URL: http:// mozdok-hutor.narod.ru/index/osobennosti3_b_alborov/0-53

2. Akhmetzyanov M.I. Nugay Urdasy: tatar khalkynyң tarikhi mirasy, ikenche kitap, Kazan Tatarstan kitab neshriyaty 2009 351 b. (na tatarskom yaz.)

3. Vinogradov V.B. Vremya, gory, lyudi. - Groznyy, 1980. S.49-55

4. Gribovskiy V.V., Sen' D.V. «Kubanskiy vektor» vo vzaimootnosheniyakh kalmykov i nogaytsev v pervoy polovine XVIII v. // Kalmyki v mnogonatsional'noy Rossii: opyt chetyrekh stoletiy. Elista: APP «Dzhangar», 2008. S. 168-192.

5.Evstigneev A. Yu. Kumany- kuny, kto oni // Obshchestvo. Sreda. Razvitie (Terra Humana), 2012. № 2. S. 91-97.

6. Istoriya Bukeevskogo khanstva. 1801-1852 gg.: sbornik dokumentov i materialov / Sost. B.T. Zhanaev, V.I. Inochkin,

S.Kh. Sagnaeva. - Almaty: Dayk-press, 2002.1120 s.

7. Ishmukhambetov R.V. Fenomen sluzhilykh grupp Bukeevskoy ordy Kaspiyskiy region // Kaspiyskiy region: politika, 
ekonomika, kul'tura. № 3 (52), 2017. S. 19-29.

8. Ishmukhambetov R.V. Povolzh'ye $i$ «polovetskoe nasledstvo»: spory i konflikty v seti Internet // XIII Kongress antropologov i etnologov Rossii: sb. materialov (Sektsiya № 22 ). Kazan', 2-6 iyulya 2019 g. / Otv. red.: M. Yu. Martynova.

- Moskva; - Kazan': IEA RAN, KFU, Institut istorii im. Sh. Mardzhani AN RT, 2019. S. 399-400.

9. Ishmukhambetov R.V. Vosstanie Isataya Taymanova 1836-1838 gg. vo Vnutrenney (Bukeevskoy) orde kazakhov $i$ sluzhilye gruppy ee naseleniya, Kaspiyskiy region: politika, ekonomika, kul'tura, 2016. № 4(49).S. 39-47.

10. Ishmukhambetov R.V. Bukeevskaya orda :traditsii, soslovnye i subetnicheskie struktury, "perekhod» identichnostey // XIII Kongress antropologov i etnologov Rossii: Kazan', 2-6 iyulya 2019 g. ( Ustnyy doklad : sektsiya № 48,4 iyulya 2019 g.)

11. Istoriya Severo-Osetinskoy ASSR. - Ordzhonikidze, 1987. T.1. 562 s.

12. Kereytov, P. X.. Nogaytsy. Osobennosti etnicheskoy istorii i bytovoy kul'tury. - Stavropol': Servisshkola. 2009.421 s.

13. Kidirniyazov D. S. Vzaimootnosheniya nogaytsev s narodami Severo-Vostochnogo Kavkaza v XVI-nachale XX v. - Makhachkala, 2008. 295 s

14. Kuzeev R. G. Proiskhozhdenie bashkirskogo naroda. Etnicheskiy sostav, istoriya rasseleniya. - M.: Nauka, 1974. $576 \mathrm{~s}$.

15. Kurumbaev A.Sh. Etnicheskie gruppy Bukeevskoy Ordy // Nogaevedcheskiy sbornik Aktual'nye voprosy istorii i kul'tury nogaytsev Vypusk 1. - Astrakhan': Izd - vo «Color», 2013. S.75-78.

16. Narodnyy epos sbornik Dagestan v legendakh i predaniyakh. -Makhachkala, 2007. $47 \mathrm{~s}$.

17. Orazaev G. M.-R. Tyurkoyazychnaya delovaya perepiska na Severnom Kavkaze XVII-XIX vv. Issledovanie, teksty i kommentarii. - Makhachkala: Izd. DNTs RAN, 2007. 322 s.

18. Plaeva Z.K. Nogayskiy variant nartovskogo predaniya o smerti Atsamaza. Nartovedenie v XXI veke: sovremennye paradigmy i interpretatsii: sbornik nauchnykh trudov. FGBUN SOIGSI VNTS RAN i RSO-A. - Vladikavkaz: IPTs SOIGSI VNTS RAN i RSO-A, 2015. $266 \mathrm{~s}$.

19. PMA - Polevye ekspeditsionnye materialy avtora. Khranyatsya $v$ ego lichnom arkhive.

20. Rychkov P.I Topografiya Orenburgskoy gubernii . - Spb.: Imperatorskaya Akademiya nauk, 1762. 331 s.

21. Ryazanov A.F Vosstanie Isataya Taymanova (1836-1838 gg.). - Tashkent: Tipolit, 1927. № 2. 103 s.

22. Sabitov Zh. M. Nogayskiy komponent v etnogeneze kazakhov // Molodoy uchenyy, 2016. № 1. S. 589-591. URL https://moluch.ru/archive/105/23264/ (data obrashcheniya: 16.07.2019).

23. Senatskiy arkhiv t. 9. - SPb, $1901 \mathrm{~g}$.

24. Trepavlov V.V. Istoriya Nogayskoy Ordy / Otv. red. M. A. Usmanov. 2-e izd. - Kazan': Izdatel'skiy dom "Kazanskaya nedvizhimost'», 2016. $764 \mathrm{~s}$.

25. Kharuzin A.N. Kirgizy Bukeevskoy ordy: antropologo-etnologich. ocherk (Izv. Ob-va LEA i E pri Moskovskom un-te. T. LXIII). Vyp. I. - M.: Tipogr. A. Levensona i K०, 1889. $338 \mathrm{~s}$.

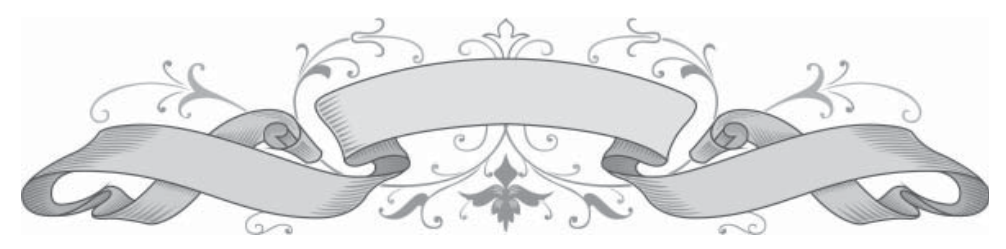

